\title{
Study of Ornamental Fish in Lalitpur, Nepal
}

\author{
Bandana Jha and Archana Prasad \\ Central Department of Zoology, Tribhuvan University, Kirtipur, Kathmandu, Nepal
}

For correspondence:archanaprasad001@gmail.com

\begin{abstract}
This work has been done from 2068 to 2069.The main theme of the survey was to find out the Aquarium fish interest among people, highest and lowest price of different fishes, feeding criteria, socio economic condition of aquarium fish trade. Survey points out that few shops are in Lalitpur. Gold fish varieties are famous among the people. Only artificial feed was given to the fishes. Increasing number of shops and satisfactory response regarding this business shows better socio economic condition regarding this sector.
\end{abstract}

Key words: Bio filter, Guppy, Parrot fish, Pearl scale, Sucker head

\section{Introduction}

Keeping a home aquarium has now become a very popular past time all over the world. It is a hobby and it appeals to young as well as old. It is very exiting to watch gentle and colourful fishes. Aquarium also adds fascinating colors to a drawing room. Besides, maintaining aquarium has also opened a flourishing business in all cities. Together all countries of the European Union are the largest market for ornamental fishes; however, the United States (US) is the single largest importer of ornamental fish in the world (Chapman 2000). Pet industry surveys have estimated the aquarium industry worth over Dollar 1,000 million USD (Cato and Brown 2003)

In cold water of mountain the Cyprinids, Schizothorax and Schizothoraichthys dominate. In high hill and hilly region they are joined by Tor, Neolissochelius, Barilius, Glyptothorax, Botia and Clupisoma (Rajbansi 1976). Zebra fish, Medaka and Xiphophorus fishes are grouped as aquarium fishes (Yang, Chen and Lan 1994).

Shop imports large varieties of ornamental fish and the other requirement like heater, filter water vibrator, medicines, fish food, purifier, net, aquarium cleaner decorating materials such as coloured stones, gravel, corals, wood, rocks and aquarium plants from India Thailand, Hongkong and Srilanka (Amatya and Gurung 2005).

\section{Materials and Methods}

Weekly visits were made up to two months at initial period followed frequent visits later in different ornamental fish shops at Lalitpur to collect information about the fish marketing system, types of fishes available; their cost price, sizes of aquarium used, source of aquarium fish supply, socio economic condition aquarium fish markets.

Nepalese Journal of Zoology | Online Volume 3 Issue 1 | November 2015 | Page 24 
Likewise, frequent visits in different houses were made for information collection regarding ornamental fishes and to know about people's interest towards this recreation. The data were collected by direct observation, through questionnaire and by phone, using a writing pad, a pen, and a camera.

\section{Results}

There are around 30 aquarium shops in Kathmandu Valley including all four districts. In Lalitpur, Kupundol, Jawalakhel, Lagankhel \& other place of this district aquarium fish shops are available. During visit to shops it showed that more than 40 types of aquarium fishes as shown in the Table 1. Out of these fishes most of them are imported from foreign country and very less native species were seen in the market.

Table 1. Fish prices at Lalitpur

\begin{tabular}{|l|l|l|}
\hline S.No. & Name of Fish & $\begin{array}{l}\text { Price } \\
\text { (NRs/2pc) }\end{array}$ \\
\hline 1 & Brown gold fish & 300 \\
\hline 2 & Lion head & 3000 \\
\hline 3 & Bubble eye & 200 \\
\hline 4 & Black mor gold & 1000 \\
\hline 5 & Red oranda & 275 \\
\hline 6 & Suban kin & 375 \\
\hline 7 & Ray kin gold & 2600 \\
\hline 8 & White gold & 300 \\
\hline 9 & Mix gold & 525 \\
\hline 10 & Red carp oranda & 275 \\
\hline 11 & Bensent tetra & 150 \\
\hline 12 & Angel fish & 1150 \\
\hline 13 & Green tiger barb & 550 \\
\hline 14 & Red eye sword tail & 150 \\
\hline 15 & Platy & 100 \\
\hline
\end{tabular}

\begin{tabular}{|l|l|l|}
\hline S. No. & Name of Fish & $\begin{array}{l}\text { Price } \\
(\mathrm{NRs} / 2 \mathrm{pc})\end{array}$ \\
\hline 16 & Serpa tetra & 125 \\
\hline 17 & Guppy & 200 \\
\hline 18 & Balloon molly & 150 \\
\hline 19 & Silver shark & 200 \\
\hline 20 & Tiger shark & 150 \\
\hline 21 & Rainbow shark & 200 \\
\hline 22 & White shark & 150 \\
\hline 23 & Red tail black shark & 200 \\
\hline 24 & Green terror & 800 \\
\hline 25 & Dollor fish & 200 \\
\hline 26 & Oscar & 1500 \\
\hline 27 & Flower horn & 3000 \\
\hline 28 & Texax & 250 \\
\hline 29 & Tinfoil barb & 350 \\
\hline 30 & Zebra fish & 400 \\
\hline
\end{tabular}

Among these fish Parrot Fish has highest price which reaches upto Rs. 20,000 per two pieces of large size available where as Gupppi has lowest price which ranges from Rs. 15 to 35 per two pieces. Concerning size of the fish, Guppi is the smallest one which has about one inch length and Shark is the largest one having length of about one \& half feet.

Only artificial feed are given to aquarium fishes, in which Tokyo, six seven, nine star optimum, C.P., Etc are famous ones. While talking about aquarium filter, three types of filter are seen i.e. physical filter, bio filter and over head filter. For decorative purpose stones, different types of statues, artificial fishes, turtle, snakes, artificial plants etc are used. In shops and few houses also natural plants like hydrilla, cocomba, amazon etc are seen.

People showed more interest in keeping gold fish varieties due to their different coloration and shape. They keep different varieties of gold fishes like Red Oranda, Black oranda, Subun kin, Calico gold, Bubble eyes, Pearl scale etc. besides they also shows their interest in fishes like Oscar, Texax, green terror, Pirana, Sweaper, Angle fish, Parrot fish and Sharks etc. Fishes like Guppy and Tetra are famous among children due to their small size, active nature and low cost. As well as Gold fishes like Ray kin,

Nepalese Journal of Zoology | Online Volume 3 Issue 1 | November 2015 | Page 25 
red Oranda, Bubble eyes are also liked by children. Decorative items like stones gravels, colorful scenery artificial fish turtle artificial plants kept in aquarium gives extra ordinary look to tank, which also helps people to increase their interest in aquarium fish keeping.

\section{Conclusion and Recommendations}

By visiting different shops in the Lallitpur suggest that more than 40 types of aquarium fishes are available. Only glass tank is made locally but it is imported from different countries. Shopkeepers in group use to import so most of them represent them self as a wholesalers. Shopkeeper not pleased with government and scholars of related field. The government agencies, NGO, INGO can play supportive role in the developing fish marketing and other related things. In this way number of increasing aquarium shops year by year in the valley is positive \& satisfactory point regarding aquarium fish trade and also indicates the public demand. For this, government sector should put forward artificial breeding programs in extensive way so that fish can made available at reliable prices \& mass killing of fish events can be lowered.

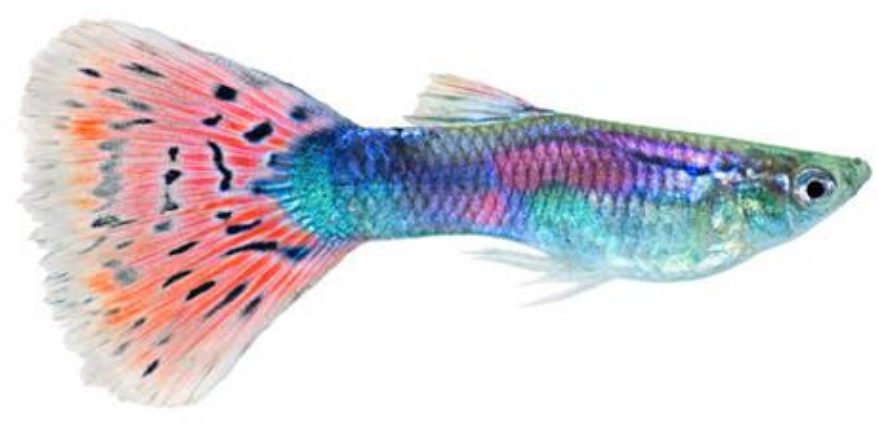

Figure 1. Parrot Fish

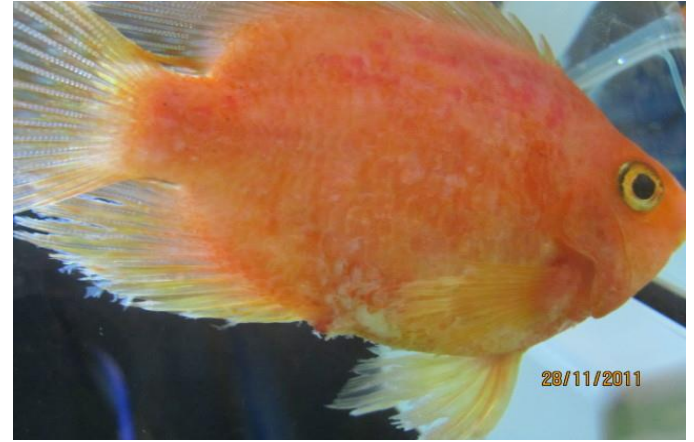

Figure 2. Guppy

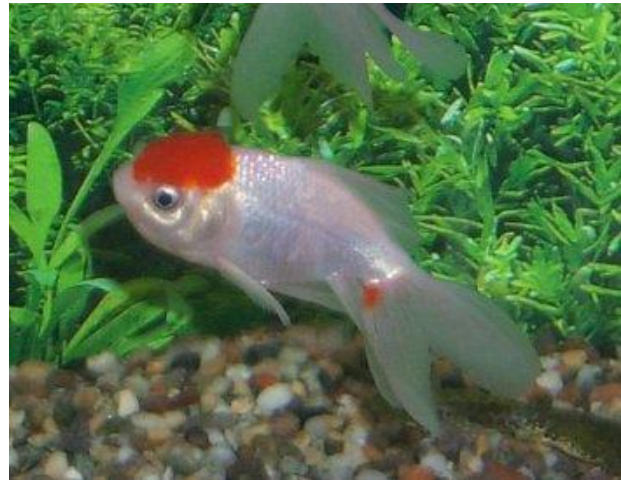

Figure 3. Red cap Oranda

Nepalese Journal of Zoology | Online Volume 3 Issue 1 | November 2015 | Page 26 


\section{References}

Amatya , B. and Gurung R. 2005. A hand book of Aquarium and Aquarium Fishes: with reference to Nepal. Swani Offset Press, Naya Bazar, Pokhara. pp:128

Cato, J. and Brown, C.L. 2003. Advancing Marine Conservation. International Marine and Fresh Water Zoological Society of London, UK

Chapman, F.A. 2000. Ornamental Fish Culture, Fresh Water, In : R.R.Stickney(Ed), Encyclopedia of Aquaculture, p. 602-610.New York, Ny: John Wiley and Sons, Inc.

Rajbansi K.G. 1976. Looping of "Snow-Trout"-Asla. J.Science, Kathmandu 6(1): 59-64

Yang, J.X., Chen Y.R. and Lan J.H. 1994. Protocobitis typhlops, a new genus and species of cave loach from fresh water, 5: 91-96

Nepalese Journal of Zoology | Online Volume 3 Issue 1 | November 2015 | Page 27 